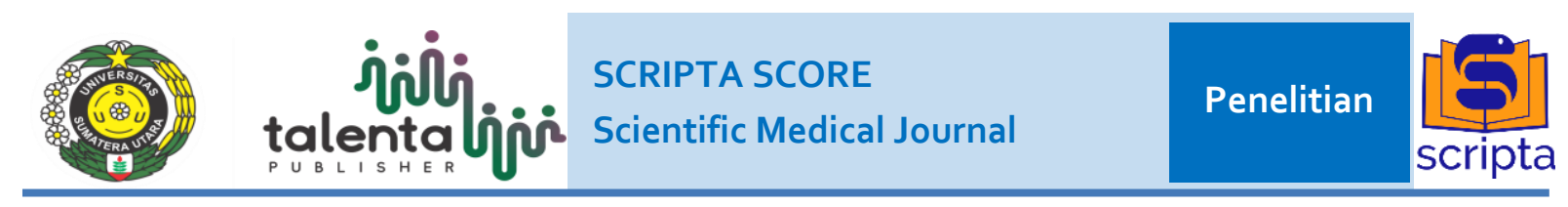

\title{
Hubungan Kadar Hemoglobin Pada Ibu di Trimester III Kehamilan Dengan Kejadian Perdarahan Pascapersalinan di RSUP Haji Adam Malik Medan
}

\author{
Bella Fitriah Paramita, Khairani Sukatendel \\ Departemen Obstetri dan Ginekologi, Fakultas Kedokteran, Universitas Sumatera Utara, Medan
}

\begin{abstract}
ABSTRAK
Latar Belakang: Angka Kematian Ibu di Indoensia pada tahun 2015 masih tinggi yaitu sebesar 305 per 100.000 kelahiran hidup. Penyebab kematian ibu tertinggi sejak satu dekade terakhir adalah karena perdarahan yaitu sebesar 30,3\% dan perdarahan pascapersalinan adalah perdarahan obstetri yang paling sering terjadi. Salah satu faktor penyebabnya adalah anemia pada ibu hamil. Tujuan: Penelitian ini bertujuan untuk mengetahui hubungan kadar hemoglobin pada ibu di trimester III kehamilan dengan kejadian perdarahan pascapersalinan. Metode: Penelitian ini menggunakan desain penelitian case control, menggunakan data sekunder yaitu rekam medik di RSUP Haji Adam Malik Medan tahun 2017 - 2018. Sampel penelitian dipilih dengan metode purposive sampling dari seluruh data rekam medik ibu dengan persalinan spontan pervaginam yang memenuhi kriteria penelitian lalu dianalisis menggunakan uji chi-square. Hasil: Dari 36 ibu dengan persalinan spontan pervaginam yang mengalami perdarahan pascapersalinan (data kasus) ditemukan bahwa ibu dengan persalinan spontan pervaginam yang mengalami perdarahan pascapersalinan dengan kadar $\mathrm{Hb}<11 \mathrm{~g} / \mathrm{dl}$ di trimester III kehamilannya sebanyak 30 orang $(83,3 \%)$ dan yang dengan kadar $\mathrm{Hb}>11 \mathrm{~g} / \mathrm{dl}$ di trimester III kehamilannya sebanyak 6 orang $(16,7 \%)$. Uji chi-square menunjukkan hasil yang signifikan ( $\mathrm{p}=0,000 ; \mathrm{OR}=7,000)$. Kesimpulan: Terdapat hubungan antara kadar hemoglobin pada ibu di trimester III kehamilan dengan kejadian perdarahan pascapersalinan.
\end{abstract}

Kata Kunci: kadar hemoglobin, perdarahan pascapersalinan, persalinan spontan pervaginam

\begin{abstract}
Background: The maternal mortality rate in Indonesia in 2015 according to the Indonesian Demographic and Health Survey (IDHS) is still high at 305 per 100,000 live births. The highest cause of maternal mortality since the last decade is due to bleeding which is $30.3 \%$ and postpartum hemorrhage is the most frequent obstetric bleeding. One of the risk factors is anemia in pregnancy. Objectives: This study aims to determine the relationship between hemoglobin levels in mothers in the third trimester of pregnancy with the incidence of postpartum hemorrhage in RSUD Haji Adam Malik Medan. Methods: This study was an analytical research study with a case-control design, using secondary data derived from medical records at RSUP Haji Adam Malik Medan in 2017 - 2018. The study sample was determined using a purposive sampling method of all medical record data that met the study criteria and then analyzed using the chi-square test. Results: From 36 mothers had postpartum hemorrhage (case group) was found that mothers who had experienced postpartum hemorrhage with anemia $(\mathrm{Hb}<11 \mathrm{~g} / \mathrm{dl})$ in the third trimester of pregnancy as many as 30 people $(83,3 \%)$ and which had normal $\mathrm{Hb}(\mathrm{Hb}>11 \mathrm{~g} / \mathrm{dl})$ in the third trimester of pregnancy as many as 6 people $(16,7 \%)$. From the chi-square test had a significant result $(p=0.000 ;$ OR $=7.000)$. Conclusion: There is an association between hemoglobin levels in mothers in the third trimester of pregnancy with the incidence of postpartum hemorrhage.
\end{abstract}

Keywords: hemoglobin levels, postpartum hemorrhage, vaginal delivery Received [31 Dec 2019] | Revised [21 Dec 2020] | Accepted [1 Jan 2021] 


\section{PENDAHULUAN}

Keberhasilan upaya kesehatan ibu, salah satunya dapat dilihat dari indikator Angka Kematian Ibu (AKI). AKI adalah jumah kematian ibu selama masa kehamilan, persalinan dan nifas yang disebabkan oleh kehamilan, persalinan dan nifas atau pengelolaannya, tetapi bukan karena sebab-sebab lain seperti kecelakaan atau cedera di setiap 100.000 kelahiran hidup. ${ }^{[1]}$

Berdasarkan Survei Demografi dan Kesehatan Indonesia (SDKI) tahun 2015, angka kematian ibu di Indonesia masih tinggi yaitu sebesar 305 per 100.000 kelahiran hidup. Angka ini sedikit menurun jika dibandingkan dengan SDKI tahun 2012, yaitu sebesar 359 per 100.000 kelahiran hidup. $^{[2]}$ Walau begitu, angka tersebut masih belum mencapai target global MDGs (Millenium Development Goals) ke-5 yaitu menurunkan Angka Kematian Ibu (AKI) menjadi 102 per 100.000 kelahiran hidup pada tahun 2015. ${ }^{[3]}$

Millenium Development Goals (MDGs) yang telah berakhir tahun 2015, kemudian dilanjutkan dengan pembangunan Sustainability Development Goals (SDGs) sampai tahun 2030. Lima penyebab kematian ibu terbesar di Indonesia tahun 2010-2013 yaitu perdarahan $(30,3 \%)$, Hipertensi dalam kehamilan $(27,1 \%)$, infeksi $(7,3 \%)$, partus lama $(1,8 \%)$, abortus $(1,6 \%)$ dan lain-lain $(31,9 \%){ }^{[3]}$

Secara umum, perdarahan obstetri dapat berupa perdarahan antepartum dan perdarahan postpartum. Perdarahan obstetrik yang lebih sering terjadi adalah perdarahan pascapersalinan. ${ }^{[4]}$ Perdarahan pascapersalinan adalah kehilangan darah secara abnormal lebih dari $500 \mathrm{ml}$ pada persalinan pervaginam dan lebih dari 1000 $\mathrm{ml}$ pada persalinan seksio sesarea. ${ }^{[5]}$

Menurut Kementerian Departemen kesehatan RI, kematian akibat perdarahan pascapersalinan dapat dicegah dengan deteksi dini faktor risiko yang menyebabkan terjadinya perdarahan pascapersalinan. Berdasarkan penelitian Yuliyati et al., 2018 faktor - faktor yang berisiko menyebabkan perdarahan pascapersalinan pada ibu hamil antara lain yaitu penolong persalinan, riwayat obstetrik buruk, interval kehamilan, riwayat abortus dan anemia dalam kehamilan. ${ }^{[6]}$

Anemia dalam kehamilan adalah kondisi ibu dengan kadar hemoglobin $<11 \mathrm{~g} \%$ pada trimester I dan III atau kadar hemoglobin < 10,5 g\% pada trimester II, nilai batas tersebut dan perbedaannya dengan kondisi wanita tidak hamil terjadi karena hemodilusi, terutama pada trimester II. ${ }^{[4]}$ Sebagian besar perempuan mengalami anemia selama masa kehamilan, baik di negara maju maupun berkembang. Badan kesehatan dunia atau Word Health Organization (WHO) memperkirakan bahwa $35-75 \%$ ibu hamil di Negara berkembang mengalami anemia. ${ }^{[7]} \mathrm{Di}$ indonesia sendiri, menurut hasil Rikesdas (Riset Kesehatan Dasar) 2018 menyatakan bahwa anemia terjadi pada $48,9 \%$ ibu hamil di Indonesia. ${ }^{[8]}$ Berdasarkan hasil survey pada tahun 2016 di Provinsi Sumatera Utara, diketahui sebanyak 40,5\% ibu hamil menderita anemia. ${ }^{[9]}$

Penelitan ini dilakukan untuk melihat hubungan antara kadar hemoglobin pada ibu hamil di trimester III dengan kejadian perdarahan pascapersalinan, dimana seperti yang telah dijelaskan, kadar hemoglobin yang rendah pada ibu hamil merupakan salah satu faktor risiko terjadinya perdarahan pascapersalinan. Perdarahan pascapersalinan merupakan penyebab utama dalam kematian ibu yang harus dicegah dengan deteksi dini faktor risiko nya agar Angka Kematian Ibu (AKI) di Indonesia menurun sebagai salah satu indikator keberhasilan upaya kesehatan ibu di Indonesia. 


\section{METODE}

Penelitian ini menggunakan metode analitik observasional dengan menggunakan desain penelitian case control. Penelitian ini dilakukan untuk mengetahui hubungan antara efek (penyakit atau kondisi kesehatan) tertentu dengan faktor risiko tertentu.

Kegiatan penelitian dilakukan di RSUP Haji Adam Medan yang dimulai pada bulan April sampai Desember 2019 yaitu dengan menggunakan data sekunder berupa rekam medis ibu dengan persalinan spontan pervaginam. Populasi pada penelitian ini adalah semua data rekam medis ibu dengan persalinan spontan pervaginam baik yang mengalami perdarahan pascapersalinan maupun yang tidak mengalami perdarahan pascapersalinan yang berjumlah 139 di RSUP H. Adam Malik Medan tahun 2017 $-2018$

Sampel kelompok kasus dalam penelitian ini diambil dengan teknik purposive sampling, dimana data yang diambil adalah data yang memenuhi kriteria inklusi dan tidak termasuk kriteria eksklusi. Kelompok kasus diambil dari data pasien ibu dengan persalinan spontan pervaginam yang mengalami perdarahan pascapersalinan. Peneliti menerapkan kriteria sampel sebagai berikut:

1. Kriteria Inkulsi

a. Ibu dengan persalinan spontan pervaginam yang mengalami perdarahan pascapersalinan (kehilangan darah secara abnormal lebih dari $500 \mathrm{ml}$ selama atau setelah kelahiran).

b. Terdapat pemeriksaan $\mathrm{Hb}$ selama trimester III kehamilan

c. Usia 20-35 tahun

d. Bayi tunggal

e. Ibu hamil yang tidak memiliki penyakit kronis

f. Tidak grande multipara (persalinan < 5) g. Ibu yang tidak memiliki riwayat polihidramnion dan oligohidramnion

h. Tidak memiliki riwayat makrosomia (badan bayi lahir < 4000 gram)

2. Kriteria Eksklusi

a. Data rekam medis tidak lengkap

b. Persalinan pervaginam dengan induksi persalinan, augmentasi persalinan, persalinan pervaginam dengan bantuan alat.

c. Perdarahan pascapersalinan karena robekan jalan lahir

d. Perdarahan pascapersalinan karena penyakit koagulasi

Sedangkan kelompok kontrol diambil dari data pasien ibu dengan persalinan spontan pervaginam yang tidak mengalami perdarahan pascapersalinan dengan jumlah yang sama dengan kelompok kasus dan diambil dengan teknik simple random sampling dengan kriteria inklusi sama dengan kelompok kasus dan kriteria eksklusi adalah data rekam medis yang tidak lengkap.

Terdapat sebanyak 36 data rekam medis ibu dengan persalinan spontan pervaginam yang mengalami perdarahan pascapersalinan yang dikategorikan sebagai kelompok kasus dan sebanyak 36 data rekam medis ibu dengan persalinan spontan pervaginam yang tidak mengalami perdarahan pascapersalinan yang dikategorikan sebagai kelompok kontrol.

Data yang telah diambil tersebut kemudian akan dianalisis dalam bentuk univariat untuk melihat distribusi frekuensi kadar hemoglobin ibu di trimester III kehamilan pada kasus yaitu ibu yang mengalami perdarahan pascapersalinan dan pada kontrol yaitu ibu yang tidak mengalami perdarahan pascapersalinan. Kemudian akan dilakukan analisis bivariat menggunakan uji chi-square untuk melihat hubungan antara kadar hemoglobin ibu hamil di trimester III (variabel independen) dengan kejadian perdarahan pascapersalinan (variabel dependen) di 
RSUP Haji Adam Malik Medan tahun $2017-2018$.

\section{HASIL}

Dari seluruh populasi ibu dengan persalinan spontan pervaginam di RSUP Haji Adam Malik Medan Tahun 2017 2018 yaitu 139 orang ibu, sebanyak 36 orang ibu dengan persalinan spontan pervaginam mengalami perdarahan pascapersalinan $(25,9 \%)$.

Tabel 1. Distribusi Frekuensi Berdasarkan Penyebab Kejadian Peradarahan Pascapersalinan Pada Ibu dengan Persalinan Spontan Pervaginam Yang Mengalami Perdarahan Pascapersalinan

\begin{tabular}{ccc}
\hline $\begin{array}{c}\text { Penyebab Perdarah } \\
\text { Pascapersalinan }\end{array}$ & Frekuensi & $\begin{array}{c}\text { Persentase } \\
(\mathbf{\%})\end{array}$ \\
\hline Retensio Plasenta & 28 & $77,8 \%$ \\
\hline Atonia Uteri & 8 & $22,2 \%$ \\
\hline Total & $\mathbf{3 6}$ & $\mathbf{1 0 0 \%}$ \\
\hline
\end{tabular}

Berdasarkan Tabel 1, dari 36 kejadian perdarahan perdarahan pascapersalinan pada ibu dengan persalinan spontan pervaginam di RSUP Haji Adam Malik Medan, didapatkan penyebab terbanyak adalah karena retensio plasenta yaitu sebanyak 28 orang ibu $(77,8 \%)$ dan diikuti

oleh atonia uteri sebanyak 8 orang ibu $(22,2 \%)$.

Tabel 2 menunjukkan bahwa dari 36 ibu dengan persalinan spontan pervaginam yang mengalami perdarahan pascapersalinan terdapat $30 \mathrm{ibu}$ yang dalam masa kehamilannya memiliki kadar hemoglobin yang rendah $(88,3 \%)$ dan terdapat 6 ibu yang dalam masa kehamilannya memiliki kadar hemoglobin yang normal $(22,5 \%)$.

Sementara itu, dari 36 ibu dengan persalinan spontan pervaginam yang menjadi kontrol yaitu yang tidak mengalami perdarahan pascapersalinan, terdapat 21 orang ibu yang dalam masa kehamilannya memiliki kadar hemoglobin normal $(58,3 \%)$ dan 15 orang ibu yang dalam masa kehamilannya memiliki kadar hemoglobin rendah $(41,7 \%)$.

Hasil uji chi- square antara variabel dependen yaitu kadar hemoglobin ibu di trimester III kehamilan dengan variabel independen yaitu kejadian perdarahan pascapersalinan didapatkan $p=0,000(\mathrm{p}<$ 0,005). Pada tabel tersebut juga menunjukkan bahwa nilai odds ratio sebesar OR $=7,000$ (CI 95\%: 2,333 21,004).

Tabel 2. Hubungan Kadar Hemoglobin Trimester III Kehamilan Dengan Kejadian Perdarahan Pascapersalinan Pada Ibu Bersalin Normal

\begin{tabular}{|c|c|c|c|c|c|c|c|}
\hline \multirow{2}{*}{$\begin{array}{c}\text { Kadar Hemoglobin } \\
\text { Trimester III } \\
\text { Kehamilan }\end{array}$} & \multicolumn{2}{|c|}{ Kasus } & \multicolumn{2}{|c|}{ Kontrol } & \multirow{2}{*}{ Total } & \multirow{2}{*}{$P$ Value } & \multirow{2}{*}{$\begin{array}{c}\text { OR } \\
(95 \% \mathrm{CI})\end{array}$} \\
\hline & $\mathbf{F}$ & $\%$ & $\mathbf{F}$ & $\%$ & & & \\
\hline Hb Rendah & 30 & 83,3 & 15 & 41,7 & 45 & \multirow{3}{*}{0,000} & \multirow{3}{*}{$\begin{array}{c}7,000 \\
(2,333-21,004)\end{array}$} \\
\hline Hb Normal & 6 & 16,7 & 21 & 58,3 & 27 & & \\
\hline Total & 36 & 100 & 36 & 100 & 72 & & \\
\hline
\end{tabular}

\section{PEMBAHASAN}

Dari hasil penelitian, didapatkan bahwa penyebab terbanyak perdarahan pascapersalinan di RSUP Haji Adam Malik Medan Tahun 2017 - 2018 adalah disebabkan karena Retensio plasenta. Hal ini sejalan dengan penelitian di RSUP Dr. M. Djamil Padang yang menyatakan bahwa penyebab terbanyak perdarahan pascapersalinan pada ibu dengan persalinan spontan pervaginam adalah retensio plasenta, yaitu sebesar 38,5\% diikuti oleh sisa plasenta $20,5 \%$, atonia uteri 5,3\% dan penyebab lain sebanyak 35,7\%. ${ }^{[11]}$ Retensio plasenta berkaitan dengan sukarnya pelepasan plasenta pada kala tiga. Saat ini sedang digencarkan tindakan manajemen aktif kala tiga, hal ini karena sebagian besar tertinggalnya sisa plasenta (retensio plasenta) dalam uterus dapat disebabkan karena kontraksi uterus yang melemah. ${ }^{[12]}$ Tingginya kasus 
retensio plasenta di RSUP H. Adam Malik Medan kemungkinan disebabkan oleh RSUP H. Adam Malik Medan merupakan salah satu rumah sakit rujukan wilayah Sumatera Utara sehingga pada penelitian ini kasus perdarahan pascapersalinan banyak dari rujukan persalinan yang telah dilakukan oleh petugas kesehatan lain sehingga banyak kasus plasenta yang masih tertahan dalam rahim sehingga menyebabkan perdarahan pascapersalinan.

Dari hasil penelitian dapat dilihat bahwa kejadian perdarahan pascapersalinan paling banyak terjadi pada ibu dengan persalinan spontan pervaginam yang memiliki kadar hemoglobin rendah pada masa kehamilannya. Hal ini sejalan dengan penelitian di RSUP Dr. M. Djamil Padang yang menunjukkan bahwa ibu dengan persalinan spontan pervaginam yang mengalami perdarahan pascapersalinan, sebanyak 92,4\% mempunyai kadar hemoglobin kurang dari $11 \mathrm{~g} / \mathrm{dl}$ pada masa kehamilannya. ${ }^{[11]}$ Pada wanita hamil, anemia meningkatkan kemungkinan terjadinya komplikasi pada kehamilan dan persalinan. Beberapa diantaranya adalah risiko kematian maternal, angka prematuritas, berat bedan bayi lahir rendah, dan angka kematian perinatal meningkat. Perdarahan antepartum dan postpartum lebih sering dijumpai pada wanita yang memiliki kadar hemoglobin rendah dalam kehamilannya dan lebih sering berakibat fatal, sebab ibu bersalin yang memiliki kadar hemoglobin rendah dalam kehamilannya tidak dapat mentoleransi kehilangan darah saat persalinan. ${ }^{[10]}$

Dari hasil penelitian ini juga menunjukkan bahwa ibu dengan persalinan spontan pervaginam yang tidak mengalami perdarahan pascapersalinan, lebih banyak yang memiliki kadar hemoglobin normal di trimester III kehamilannya dibandingkan dengan ibu yang memiliki kadar hemoglobin rendah di trimester III kehamilannya. Hal ini sejalan dengan penelitian di RSUD Dr. Soedarso Kota Pontianak yang menunjukkan bahwa ibu dengan persalinan spontan pervaginam yang tidak mengalami perdarahan pascapersalinan lebih banyak yang memiliki kadar hemoglobin normal pada masa kehamilannya yaitu sebanyak $53,6 \%$. ${ }^{[13]}$

Hasil uji chi-square antara variabel dependen yaitu kadar hemoglobin ibu di trimester III kehamilan dengan variabel indepen yaitu kejadian perdarahan pascapersalinan didapatkan nilai $p$ value sebesar $p=0,000(\mathrm{p}<0,005)$. Hal ini menunjukkan bahwa terdapat hubungan yang signifikan antara kadar hemoglobin ibu di trimester III kehamilan dengan kejadian perdarahan pascapersalinan pada ibu dengan persalinan spontan pervaginam. Hasil penelitian juga menunjukkan bahwa nilai odds ratio adalah sebesar OR = 7,000 (CI 95\%: 2,333 - 21,004) yang berarti bahwa, ibu dengan persalinan spontan pervaginam yang mempunyai kadar hemoglobin rendah dalam kehamilannya mempunyai risiko 7 kali lebih besar untuk mengalami perdarahan pascapersalinan dibandingkan dengan ibu yang mempunyai kadar hemoglobin normal dalam kehamilannya.

Hal ini sesuai dengan penelitian tentang analisis hubungan anemia dengan perdarahan pascapersalinan di RSUD Ahmad Yani Kota Metro Provinsi Lampung yang menyatakan bahwa terdapat hubungan antara anemia pada ibu hamil dengan kejadian perdarahan pascapersalinan $(p=0,000)$ dengan nilai $\mathrm{OR}=5,313$ yang berarti ibu yang mengalami anemia atau mempunyai kadar hemoglobin rendah dalam kehamilannya berisiko 5 kali lebih besar mengalami perdarahan pascapersalinan dibandingkan dengan ibu yang tidak mengalami anemia atau mempunyai kadar hemoglobin normal dalam kehamilannya. ${ }^{[14]}$ Hal ini juga didukung dengan hasil penelitian di RSUD Undata Palu Provinsi Sulawesi Tengah yang menjelaskan bahwa terdapat hubungan yang signifikan antara kadar hemoglobin rendah dengan kejadian 
perdarahan pascapersalinan $(\mathrm{p}=0,000)$ dengan $\mathrm{OR}=28,571 .^{[15]}$

Dalam penelitian ini, ibu dengan persalinan spontan pervaginam yang mengalami perdarahan pascapersalinan sebagian besar memiliki kadar hemoglobin yang rendah pada saat kehamilannya $(83,3 \%)$. Ibu bersalin yang memiliki kadar hemoglobin rendah pada masa kehamilannya akan dengan cepat terganggu kondisinya bila terjadi kehilangan darah meskipun hanya sedikit, anemia dihubungkan dengan kelemahan yang dapat dianggap sebagai penyebab langsung perdarahan pascapersalinan. Risiko perdarahan pascapersalinan meningkat pada wanita bersalin dengan anemia, dimana uterus kekurangan oksigen, glukosa serta nutrisi esensial dan cenderung bekerja tidak efisien pada semua persalinan, hal ini lah yang dapat menyebabkan perdarahan pascapersalinan semakin meningkat dan memiliki prognosis yang buruk. ${ }^{[16]}$ Ibu dengan persalinan spontan pervaginam yang memiliki kadar hemoglobin rendah pada saat kehamilannya akan mengakibatkan berkurangnya kemampuan ibu untuk bertahan pada saat persalinan. Karena kadar hemoglobin yang rendah dapat mengakibatkan proses metabolisme energi menjadi terhambat karena kekurang pasokan oksigen. Metabolisme energi yang rendah akan membuat otot uterus tidak berkontraksi secara maksimal. ${ }^{[17]}$ Jika otot uterus tidak dapat berkontraksi secara maksimal maka akan terjadi gangguan his pada ibu bersalin hal ini dapat menyebabkan berbagai masalah, kala I dapat berlangsung lama, kala II dapat berlangsung lama sehingga dapat melelahkan dan sering memerlukan tindakan operasi, kala III dapat terjadi retensio plasenta yang diikuti perdarahan pascapersalinan dan kala IV dapat terjadi atonia uteri. ${ }^{[18]}$

Keterbatasan dalam melakukan penelitian hubungan anemia dalam kehamilan dengan kejadian perdarahan pascapersalinan primer di RSUD $\mathrm{H}$.
Adam Malik Medan yaitu pada penelitian ini tidak terdapat data mengenai variabel IMT, status nutrisi, usia, paritas, usia kehamilan, apakah menerima tablet besi, jumlah kunjungan ANC sehingga tidak diketahui dengan pasti faktor-faktor yang menyebabkan anemia pada ibu hamil dan juga dapat menjadi variabel lain yang dapat mempengaruhi kejadian perdarahan pscapersalinan walaupun peneliti sudah meminimalkan bias menggunakan kriteria insklusi dan eksklusi.

\section{KESIMPULAN}

Berdasarkan hasil penelitian dari ibu dengan persalinan persalinan spontan pervaginam yang mengalami perdarahan pascapersalinan, persentase paling banyak adalah ibu yang memiliki kadar hemoglobin rendah di trimester III kehamilannya dan ibu yang menjadi kontrol, yaitu ibu dengan persalinan persalinan spontan pervaginam yang tidak mengalami perdarahan pascapersalinan, persentase paling banyak adalah ibu yang memiliki kadar hemoglobin normal di trimester III kehamilannya.

Dari hasil uji chi-square menunjukkan bahwa terdapat hubungan yang signifikan antara kadar hemoglobin pada ibu hamil di trimester III kehamilan dengan kejadian perdarahan pascapersalinan. Berdasarkan nilai odds ratio menunjukkan bahwa ibu dengan persalinan spontan pervaginam yang memiliki kadar hemoglobin rendah di trimester III kehamilannya memiliki risiko 7 kali lebih besar mengalami perdarahan pascapersalinan dibandingkan dengan ibu dengan persalinan spontan pervaginam yang memiliki kadar hemoglobin normal di trimester III kehamilannya.

SARAN
Penelitian menyarankan bahwa
Penelitian ini perlu dianalisis lebih lanjut
dengan melakukan analisis data
dikarenakan pada penelitian ini hanya
dianalisis satu faktor penyebab perdarahan


pascapersalinan yaitu ibu bersalin yang memiliki kadar hemoglobin rendah dalam kehamilannya. Walaupun peneliti telah meminimalkan bias menggunakan kriteria inklusi dan eksklusi, tetapi agar dapat mengetahui lebih jelas faktor penyebab perdarahan pascapersalinan, diperlukan penelitian penelitian lebih lanjut menggunakan faktor - faktor penyebab perdarahan pascapersalinan yang lain.

\section{DAFTAR PUSTAKA}

[1] Kementerian Kesehatan Republik Indonesia. Profil Kesehatan Indonesia 2017. Jakarta: Kementerian Kesehatan Republik Indonesia; 2017.

[2] Bappenas. Pengarusutamaan Kesehatan Dalam Sustainable Development Goals (SDGs). Jakarta: Badan Perencanaan Pembangunan Nasional; 2017.

[3] Kementerian Kesehatan Republik Indonesia. Profil Kesehatan Indonesia 2014. Jakarta: Kementerian Kesehatan Republik Indonesia; 2014.

[4] Cunningham FG, Leveno KJ, Bloom SL, Hauth JC, Rouse DJ, Spong CY. Obstetri Williams. $23^{\text {rd }}$ ed. Setia R, editors. Jakarta: EGC; 2012.

[5] Prawirohardjo S. Ilmu kebidanan. 4 ed. Saifuddin BA, editors. Jakarta: Bina Pustaka; 2016.

[6] Yuliyati A, Soejoenoes A, Suwondo A, Kartasurya MI. Beberapa Faktor Kejadian Perdarahan Postpartum Ibu Bersalin yang Dirawat di Rumah Sakit. E-Journal Martenity and Neonatal. 2018;3(1):7-17. doi: $\underline{10.14710 / j e k k . v 3 i 1.3101}$

[7] World Health Organization. Haemoglobin Concentrations for the Diagnosis of Anaemia and Assessment of Severity. Mineral Nutrition Information System, Geneva: World Health Organization; 2011. pp. 1-6

[8] Kementerian Kesehatan Republik
Indonesia. Hasil Utama Riskesdas 2018. Jakarta: Kementerian Kesehatan Republik Indonesia; 2018.

[9] Dinas Kesehatan Kota Medan 2016, 'Profil Kesehatan Kota Medan Tahun 2016'.

[10] Hikmah N, Yani D. Gambaran Hemoragic Post Partum Pada Ibu Bersalin Dengan Kejadian Anemia di Ruang Ponek RSUD Kabupaten Jombang. Jurnal Edu Health. 2015;5(2):144.

[11] Ramadhan JW, Rasyid R, Rusnita D. Profil pasien hemorrhagic postpartum di RSUP Dr. M. Djamil. Jurnal Kesehatan Andalas. 2019;8(Suppl 2): 46-53. doi: 10.25077/jka.v8i2S.958

[12] Yuliawati, Anggraini Y. Hubungan riwayat pre eklamsia, retensio plasenta, atonia uteri dan laserasi jalan lahir dengan kejadian perdarahan post partum pada ibu nifas. Jurnal Kesehatan. 2015;6(1):75-82.

[13] Yuniarty Y, Putri DK. Hubungan Anemia dalam Kehamilan dengan Kejadian Perdarahan Post Partum Primer pada Ibu Post Partum; 2015.

[14] Lestari GI. Analisis Hubungan Anemia Dengan Perdarahan Postpartum Di RSUD Jendral Ahmad Yani Kota Metro Tahun 2013. Jurnal Kesehatan Metro Sai Wawai, 2014;7(2):69.

[15] Sumiati, Udin, Aminuddin. Anemia Kehamilan dan Jarak Persalinan Dengan Kejadian Perdarahan Postpartum di RSUD Undata Palu Propinsi Sulawesi Tengah. Husada Mahakam: Jurnal Kesehatan. 2017;4(5):315-25. doi: 10.35963/hmjk.v4i5.104

[16] Satriyandari Y, Hariyati NR. FaktorFaktor Yang Mempengaruhi Kejadian Perdarahan Postpartum. Journal of Health Studies. 2017;1(1):49-64. doi: $\underline{10.31101 / \text { jhes. } 185}$ 
[17] Siagian R, Sari RD, Ristyaning P. Hubungan Tingkat Paritas dan

Tingkat Anemia terhadap Kejadian Perdarahan Postpartum pada Ibu Bersalin. Jurnal Majority. 2017;6(3):45-50.

[18] Manuaba. Ilmu Kebidanan, Penyakit Kandungan dan KB. $2^{\text {nd }}$ ed. Jakarta: EGC; 2013. 